\title{
Gecikmiş İnfantil Hipertrofik Pilor Stenozu: Ultrasonografi Parametrelerinin Yaşa Göre Dağılımı
}

\section{Delayed Infantile Hypertrophic Pyloric Stenosis: Age Distribution by Ultrasonography Parameters}

\author{
$\underline{\text { Mehmet TAHTABASSI }}{ }^{1}{ }^{\mathbb{D}}$, Mehmet KOLU $^{2}{ }^{\mathbb{D}}$, Mustafa Erman DÖRTERLER ${ }^{3}$ (D)
}

\author{
1 Sağlık Bilimleri Üniversitesi, Mehmet Akif Inan Eğitim ve Araşıırma Hastanesi, Radyoloji Kliniği, Şanlıurfa, Türkiye \\ 2 Harran Üniversitesi, Tıp Fakültesi, Radyoloji Anabilim Dalı, Şanlıurfa, Türkiye \\ 3 Harran Üniversitesi, Tıp Fakültesi, Çocuk Cerrahisi Anabilim Dalı, Şanlıurfa, Türkiye
}

Öz.

Amaç: Bu çalışmada, infantil hipertrofik pilor stenozu (IHPS) taniı term infantlarda ultrasonografi (USG) parametrelerinin (pilor kası boyutları) yaş ile korelasyonunun değerlendirimesi amaçlandı.

Materyal ve metod: Kasım 2015 ve Aralık 2019 tarihleri arasında, IHPS tanısı alıp piloromiyotomi ameliyatı yapılan 49 hastanın verileri retrospektif olarak analiz edildi. Hastaların demografik ve laboratuvar verileri elektronik medikal kayitlarından elde edildi. Pilor kas kalınıı̆ıı (PK), pilor çapı (PÇ) ve pilor kas uzunluğu (PU) gibi USG parametreleri ayrı ayrı ölçüldü. Pilorik ölçümlerin yaşa göre dağıımını değerlendirmek amacıyla term infantlar neonatal ( 0 - 28 gün) ve postneonatal (29 - 364 gün) olmak üzere iki gruba ayrıldı. Preterm infantlar (gebelik yaşı <37 hafta) ile birlikte klinik verilerine ve ultrasonografi görüntülerine ulaşılamayan infantlar çalışma dışı bırakıldı. Bulgular: Çalışmaya dahil edilen 32 hastanın $24(\% 75)$ ' ü erkek ve 8 (\%25)'i kız olup, başvuru anında infantların ortalama yaşı 57.8 ve median (minimum-maksimum) değeri 57.5 (9-180) gün idi. Tüm hastalarda lümeni daraltan, elonge ve kalın görünümde hipertrofik pilor kası tespit edildi. Tüm vakalarda distandü midede peristaltizm artışı ve mide içeriğinin duodenuma geçişinin olmaması veya yavaşlaması mevcuttu. Neonatal dönemde $15(\% 46.9)$ ve postneonatal dönemde 17 (\%53.1) infant mevcuttu. Ameliyat öncesi hastalara yapılan ölçümlerde PK, PC ve PU yüksekti (median değer sırasıyla; 4.8, 11.2 ve $19.5 \mathrm{~mm}$ ). Neonatal ve postneonatal dönemdeki infantların pilorik ölçümleri her iki grup arasında benzer olup istatistiksel olarak anlamlı farklılık saptanmadı $(p>0.05)$. Yapılan korelasyon analizinde PK ile PU $(r=0.490, p=0.033)$ ve PK ile PÇ arasında $(r=0.741, p<0.001)$ anlamlı oranda pozitif korelasyon mevcuttu. Ancak yaş ile pilorik ölçümler arasında anlamlı korelasyon saptanmadı $(p>0.05)$. Laboratuvar verileri açısından karşılaştırma yapıldığında postneonatal dönemdeki infantlarda neonatal gruba göre hemoglobin değerleri anlamlı olarak düşük bulundu (sırasıyla $11 \pm 1.5$ ve $13.7 \pm 2.7 \mathrm{~g} / \mathrm{dL} ; \mathrm{p}<0.001)$.

Sonuç: IHPS tanısında kullanılan USG iyonizan radyasyon içermemesi, yüksek duyarılılı̆ı ve dinamik inceleme yapılabilmesi gibi avantajları nedeniyle, ilk tercih edilmesi gereken etkili ve güvenilir bir görüntüleme yöntemidir. Pilor kas ölçümleri tanı için değerli olmakla birlikte yaş ve kas boyutları arasında anlamlı korelasyon olmadığı sonucuna varıldı.

Anahtar kelimeler: Hipertrofik pilor stenozu, İnfant, Mide çıkış obstrüksiyonu Ultrasonografi, Yaş

Abstract

Background: In this study, it was aimed to evaluate the correlation of ultrasonography (USG) parameters (pyloric muscle sizes) with age in term infants diagnosed with infantile hypertrophic pyloric stenosis (IHPS).

Materials and Methods: Data of 49 patients diagnosed with IHPS between November 2015 and December 2019 and underwent pyloromyotomy surgery were retrospectively analyzed for this study. The demographic and laboratory data were obtained from the electronic records of the patients. USG parameters such as pyloric muscle thickness (PMT), pyloric diameter (PD), and pyloric muscle length (PML) were measured separately. Term infants were divided into two groups as neonatal (0-28 days) and postneonatal (29-364 days) in order to compare the distribution of USG parameters by age. Infants whose clinical data and USG images were not available together with preterm infants (gestational age $<37$ weeks) were excluded from the study.

Results: Of the 32 patients included in the study, $24(75 \%)$ were male and $8(25 \%)$ were female, and the mean age of the infants was 57.8 days and the median (minimum-maximum) value was 57.5 (9-180) days at the time of admission. In USG examinations, the hypertrophic pyloric muscle was detected in elongated and thick appearance, narrowing the lumen in all patients. There were $15(46.9 \%)$ infants in the neonatal period and $17(53.1 \%)$ in the postneonatal period. In the preoperative measurements, PMT, PD, and PML were high (median value; 4.8, 11.2 and $19.5 \mathrm{~mm}$, respectively). The pyloric measurements of infants in the neonatal and postneonatal period were similar between the two groups, and there was no statistically significant difference $(p>0.05)$. The correlation between PMT and PML $(r=0.490, p=0.033)$ and the correlation between PMT and PD $(r=0.741, p<0.001)$ were significant. However, no significant correlation was found between age and pyloric measurements $(p>0.05)$. When comparing laboratory data, hemoglobin values were significantly lower in infants in the postneonatal period compared to the neonatal group $(11 \pm 1.5$ and $13.7 \pm 2.7 \mathrm{~g} / \mathrm{dL} ; \mathrm{p}<0.001$, respectively).

Conclusion: Due to the advantages of USG ionizing radiation used in the diagnosis of IHPS, high sensitivity, and dynamic examination, it is an effective and reliable imaging method that should be preferred first. Although pyloric measurements are valuable for diagnosis, it has been concluded that there is no significant correlation between age and pyloric sizes.

Key words: Age, Gastric outlet obstruction, Hypertrophic pyloric stenosis, Infant, Ultrasonography

\section{Sorumlu Yazar I \\ Corresponding Author}

Mehmet Tahtabaşı

Sağlık Bilimleri Üniversitesi, Mehmet Akif İnan Eğitim ve Araştırma Hastanesi,

Esentepe mah. Ertuğrul cad. 63050 Şanlıurfa, Türkiye

Tel: +90414318 6000 ,

+905076159932

E-mail:

mehmet.tahtabasi@sbu.edu.tr

Geliş tarihi / Received: 06.05.2020

Kabul tarihi / Accepted: 06.07.2020

DOI: $10.35440 /$ hutfd. 733290 


\section{Giriş}

Infantil hipertrofik pilor stenozu (IHPS), mide çıkışındaki pilor kasının hipertrofisi sonucu pilor kanalının obstrüksiyonu ile karakterizedir. İnsidansı 1000 canlı doğumda 1-4 olup erkeklerde kızlara göre 3-5 kat daha sık görülmektedir. Tipik olarak yaşamın ilk 3-6 haftasında, öncelikle birkaç kez ve sonra sıklığı gittikçe artan projektil safrasız kusmalarla karakterize olan ve nedeni tam bilinmeyen bir hastalıktır (1). Fizik muayenede epigastrik bölgede ele gelen kitle (olive mass) ile karakterizedir. Hastalar hipokloremik metabolik alkaloz ve dehidratasyon ile prezente olurlar. Bu durum devam ederse yaşamı tehdit eden ölümcül durum ortaya çıkabilir (2). Son yıllarda tanıda ultrasonografi (USG)'nin önemi gittikçe artmıştır. Doğru bir teknikle yapılan USG'nin duyarıı̆ığı \%100'e kadar ulaşmaktadır. Sonografik tanı için pilor kas kalınlığı (PK), pilor çapı (PÇ) ve pilor uzunluğu (PU) gibi parametreler değerlendirilmekte olup, bunların yaş ve kilo gibi klinik verilerle değiştiğine dair literatürde farklı görüşler bildirilmiştir (3). Bu çalışmada IHPS tanılı term bebeklerde pilor kas ölçümleri ile yaş arasında korelasyon olup olmadığının değerlendirilmesi amaçlandı.

\section{Materyal ve Metod \\ Hastaların verileri}

Bu çalışma için hastanemizde Kasım 2015 ve Aralık 2019 tarihleri arasında, İHPS tanısı alıp piloromiyotomi ameliyatı yapılan 49 hastanın verileri retrospektif olarak analiz edildi. Gebelik yaşı $<37$ hafta olan 8 preterm bebek, ameliyat verileri ve klinik bilgileri belirtilmeyen 4 bebek ve USG görüntülerine ulaşılamayan 5 bebek çalışma dışı bırakıldı. Sonuçta bu çalışmaya cerrahi ile IHPS tanısı doğrulanan 32 hasta dahil edildi. Bu retrospektif tek merkezli çalışma için yerel etik kurul onayı alındı (Somali Türkiye Mogadişu Recep Tayyip Erdoğan Eğitim ve Araştırma Hastanesi26.12.2019 - MSTH/200). Hastaların demografik (yaş, cinsiyet) ve laboratuvar verileri elektronik medikal kayıtlarından elde edildi. USG parametrelerinin (PK, PÇ ve PU) yaşa göre dağılımını karşılaştırmak amacıyla başvuru anında hesaplanan yaş kriter alınarak, term infantlar neonatal $(0$ 28 gün) ve postneonatal ( 29 - 364 gün) olmak üzere iki gruba ayrıldı (4) (Şekil 1).

Ultrasonografi tekniği ve antro-pilorik bölgenin değerlendirilmesi

USG görüntüleri hastane görüntüleme arşiv sisteminden elde edildi. USG'de pilor kası ölçümleri (PK, PÇ ve PU) ve mide içeriğinin duodenuma geçişi değerlendirildi. Bütün ölçümler ve değerlendirmeler 6 ve 8 yıllık USG tecrübesi olan iki radyolog tarafindan ortak bir kararla, aynı teknikle ve standart bir şekilde yapıldı. USG muayeneleri $7.5 \mathrm{MHz}$ yüksek frekanslı lineer prop (Canon Aplio 500, Otawara, Japan) kullanılarak yapıldı. Oral alımı olan bebeklerin annesi tarafından emzirilmesinden sonra ve nazogastrik tüpü olanların ise tüp içerisinden vücut sıcaklığındaki steril izotonik mayinin verilmesini takiben işleme başlandı. Kullanılan USG jelinin bebeği rahatsı etmeyecek şekilde uygun sıcaklıkta olmasına dikkat edildi.

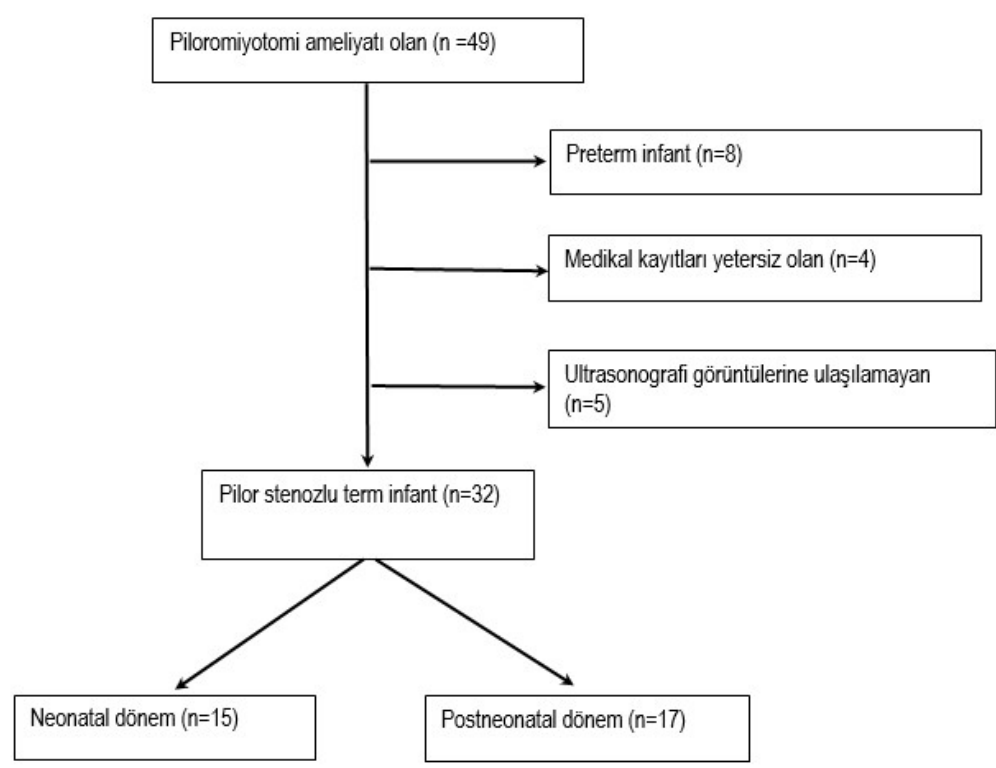

Şekil 1. Akış diagramı. Çalışmaya dahil edilme ve çalışma dışı bırakılma kriterleri

Tüm hastaların USG muayeneleri supin pozisyonda ve 4590 derece sol yana dönük şekilde yapıldı. USG probunu transvers pozisyonda tutarak veya saat yönünün tersine hafif çevirerek safra kesesi görüntülenmesini takiben, safra kesesinin hafif medial ve posteriorundaki pilor kası değerlendirildi. Yanlış ölçümleri engellemek için tanjansiyel açı verilmesinden ve pilor kasının kontraksiyonu sırasında ölçüm yapmaktan kaçınıldı. Her bir ölçüm iki defa yapılıp ortalaması alındı. Pilor kasının hipoekoik lineer şekilde görülmesi ile transvers ve longitudinal bakıda PK ölçüldü. Kasın dışından mukozanın dışına doğru ölçüm yapıldı. Merkezimizde IHPSS tanısı için PK $\geq 3$ mm olarak kabul edildi (5, 6). Transvers görüntülerde kas tabakasının dış kenarından karşı taraf kasın dış kenarına kadar, lümenin en dar olduğu yerde PÇ ölçüldü. Son olarak PU longitudinal planda duodenumun başlangıcından mide antrumuna kadar olacak şekilde ölçüldü. Aynı zamanda dinamik USG muayenesi ile pilor stenozu tanısı doğrulandı. Mide içeriğinin duodenuma geçişinin olmaması/gecikmesi ve gastroözofageal reflü görülmesi pilor stenozunu destekleyen bulgular olarak kabul edildi.

Istatistiksel analiz

Bütün analizler SPSS 20.0 (Chicago, IL, USA) yazılımı ile yapıldı. Değişkenler kategorik ve devamlı olmak üzere iki gruba ayrıldı. Kategorik değişkenler sıklık ve yüzde olarak, devamlı değişkenler ortalama ve standart sapma, median değer (minimum-maksimum) olarak verildi. Kategorik de- 
ğişkenleri karşılaştırmak için ki-kare testi kullanıldı. Devamlı değişkenlerin normal dağılıp dağılmadığını değerlendirmek için Shapiro-Wilk testi kullanıldı. Devamlı değişkenlerde normal dağılım göstermeyen parametreler MannWhitney $\mathrm{U}$ testi, normal dağılım gösterenler student $\mathrm{t}$ testi kullanılarak karşılaştıııldı. Spearman korelasyon testi ile yaş ve USG parametreleri (PK, PÇ ve PU) arasında korelasyon olup olmadığı analiz edildi. $P<0.05$ olanlar istatiksel olarak anlamlı kabul edildi.

\section{Bulgular}

Çalışmaya dahil edilen hastaların 24 (\%75)' ü erkek ve 8 (\%25)'i kız olup, başvuru anında infantların ortalama yaşı $57.8 \pm 37.4$ gün (aralık, 9-180 gün) idi. Tüm hastalarda safrasız kusma mevcuttu. Sağ üst kadranın medialine yapılan USG muayenelerinde tüm hastalarda lümeni daraltan, elonge ve kalın görünümde hipertrofik pilor kası tespit edildi. Tüm vakalarda distandü midede peristaltizm artışı ve mide içeriğinin duodenuma geçişinin olmaması veya yavaşlaması mevcuttu. Hastaların tamamında transvers düzlemde target sign-hedef bulgusu, longitudinal düzlemde ise antruma doğru mide mukozasının protrüzyonu (antral nipple bulgusu) ve pilor kas kitlesinin indentasyonu (serviks bulgusu) mevcuttu (Şekil 2 ve 3).

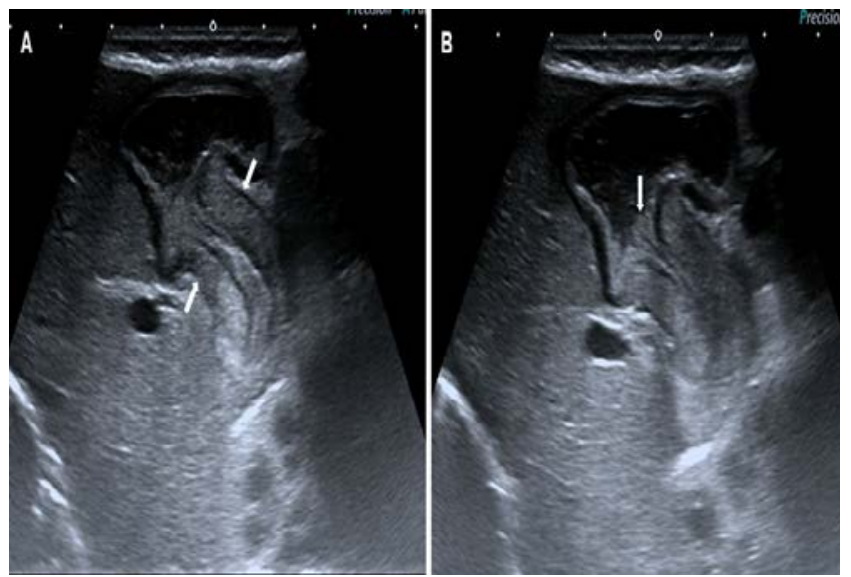

Şekil 2. Pilor stenozu olan infantın longitudinal düzlemdeki USG görüntüleri. Oral beslenme sonrası yapılan abdominal USG görüntüleri

A) lümeni daraltan hipertrofik pilor kasını (oklar) ve

B) pilor mukozasının mide antrumuna protrüde (antral nipple bulgusu) olduğunu gösteriyor (ok).

Neonatal dönemde $15(\% 46.9)$ ve postneonatal dönemde 17 (\%53.1) infant mevcuttu. Tablo 1'de gösterildiği gibi tüm hastalara yapılan ölçümlerde PK, PÇ ve PU değerleri normalin üstünde tespit edildi (median değer sırasıyla; 4.8, 11.2 ve $19.5 \mathrm{~mm}$ ). Hastaların 8 (\%25)'inde PK değeri 3-4 $\mathrm{mm}$ aralığında ölçüldü. Neonatal ve postneonatal dönemdeki infantların PK, PÇ ve PU değerleri her iki grup arasında benzer olup istatistiksel olarak anlamlı farklılık saptanmadı (sırasıyla $p=0.893, p=0.537$ ve $p=0.582$ ). Yapılan korelasyon analizinde PK ile PU $(r=0.490, p=0.033)$ ve PK ile PÇ arasında ( $r=0.741, p<0.001)$ anlamlı oranda pozitif korelasyon mevcuttu (Şekil 4). Ancak yaş ile USG parametreleri (PK, PÇ ve PU) arasında anlamlı korelasyon saptanmadı (Tablo 2).
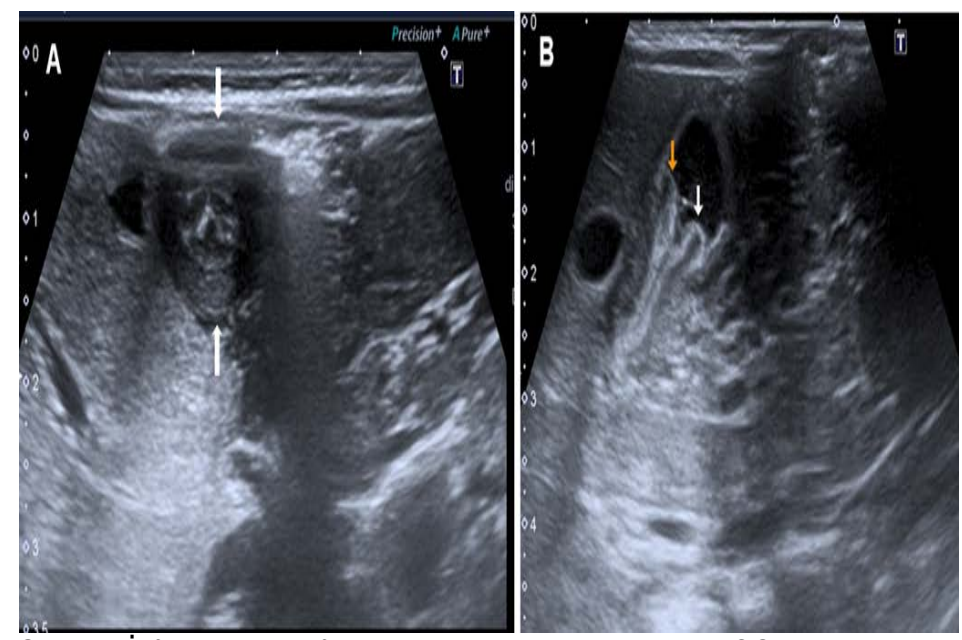

Şekil 3. İnfantil hipertrofik pilor stenozlu term bebeğin USG görüntüleri.

A) Abdominal USG görüntüleri transvers düzlemde santralde ekojen mukoza ve periferinde halkasal şekilde hipertrofik pilor kasını (target sign-hedef bulgusu) gösteriyor (oklar).

B) Longitudinal görüntüler antruma indente olmuş pilor kasını (oklar) gösteriyor (serviks bulgusu).

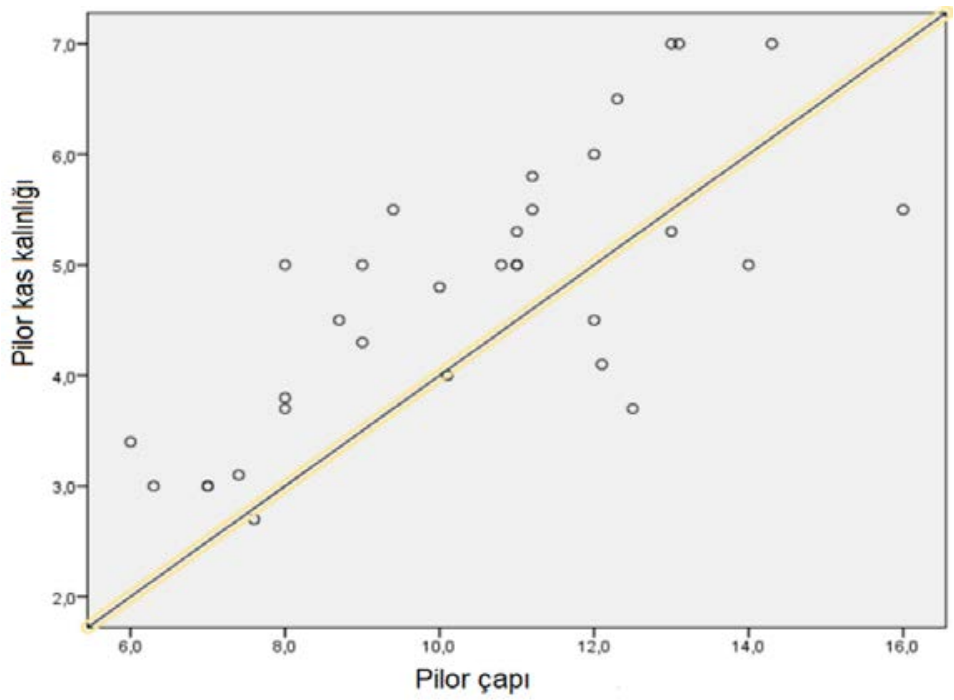

Şekil 4. Scatter grafiği pilor kas kalınlığı ve pilor çapı arasında pozitif korelasyon olduğunu gösteriyor.

Laboratuvar verileri açısından karşılaştırma yapıldığında postneonatal dönemdeki infantlarda neonatal gruba göre hemoglobin değerleri anlamlı olarak düşük bulundu (sırasiyla $11 \pm 1.5$ ve $13.7 \pm 2.7 \mathrm{~g} / \mathrm{dL} ; p<0.001$ ). Diğer laboratuvar verileri her iki grup arasında benzerdi (Tablo 3 ).

Başvuru anında hastaların 20 (\%62.5)'sinde hiponatremi, 28 (87.5)'inde hipokloremi, 16 (\%50)'sında hipopotasemi, 8 (\%25)'inde hipoglisemi, 15 (\%46.9)'inde anemi ve 16 (\% 50 )'sında düşük kreatinin değerleri tespit edildi (Tablo 4). 
Tablo 1. Neonatal ve postneonatal gruplar arasındaki ultrasonografi parametrelerinin Mann-Whitney $U$ testi ile karşılaştırıması

\begin{tabular}{|c|c|c|c|c|}
\hline & $\begin{array}{l}\text { Tüm } \\
\text { hastalar }\end{array}$ & $\begin{array}{c}\text { Neonatal } \\
n=15\end{array}$ & $\begin{array}{l}\text { Post } \\
\text { neonatal } \\
n=17\end{array}$ & $\begin{array}{l}P \\
\text { değerleri }\end{array}$ \\
\hline $\begin{array}{l}\text { Pilor uzunluğu } \\
(\mathrm{mm})\end{array}$ & $\begin{array}{l}19.5 \\
(5.6-26.0)\end{array}$ & $\begin{array}{l}17.9 \\
(16.4-22.1)\end{array}$ & $\begin{array}{l}20.0 \\
(15.1-26.2)\end{array}$ & 0.582 \\
\hline $\begin{array}{l}\text { Pilor kas kalınlığı } \\
(\mathrm{mm})\end{array}$ & $\begin{array}{l}4.8 \\
(2.7-7.2)\end{array}$ & $\begin{array}{l}3.7 \\
(2.7-5.8)\end{array}$ & $\begin{array}{l}4.5 \\
(3.0-6.1)\end{array}$ & 0.893 \\
\hline Pilor çapı (mm) & $\begin{array}{l}11.2 \\
(6.3-6.4)\end{array}$ & $\begin{array}{l}11.2 \\
(6.0-12.5)\end{array}$ & $\begin{array}{l}8.7 \\
(7.2-16.0)\end{array}$ & 0.537 \\
\hline
\end{tabular}

Tablo 2. Yaş ve ultrasonografi parametreleri arasında yapılan Spearman korelasyon analizleri

\begin{tabular}{|l|l|l|l|l|l|}
\hline \multirow{2}{*}{} & & Yaş & $\begin{array}{l}\text { Pilor } \\
\text { uzunluğu }\end{array}$ & Pilor kas kalınlığı & Pilor çapı \\
\hline Yaş & $\mathrm{r}$ & 1 & -0.097 & -0.121 & 0.128 \\
\cline { 2 - 6 } & $p$ & - & 0.668 & 0.564 & 0.709 \\
\hline $\begin{array}{l}\text { Pilor } \\
\text { uzunluğu }\end{array}$ & $\mathrm{r}$ & -0.097 & 1 & $0.490^{\star}$ & 0.552 \\
\cline { 2 - 6 } & $p$ & 0.668 & - & 0.033 & 0.078 \\
\hline $\begin{array}{l}\text { Pilor kas } \\
\text { kalınlığı }\end{array}$ & $\mathrm{r}$ & -0.121 & $0.490^{\star}$ & 1 & $0.741^{\star}$ \\
\cline { 2 - 6 } & $p$ & 0.564 & 0.033 & - & $<0.001$ \\
\hline \multirow{2}{*}{ Pilor çapı } & $\mathrm{r}$ & 0.128 & 0.552 & $0.741^{\star}$ & 1 \\
\cline { 2 - 6 } & $p$ & 0.709 & 0.078 & $<0.001$ &. \\
\hline
\end{tabular}

${ }^{*} p$ değeri < 0.05 olması anlamlı korelasyon olduğunu göstermektedir.

Tablo 3. Neonatal ve postneonatal grup arasında laboratuvar parametrelerinin student $t$ testi ile karşılaştırılması

\begin{tabular}{|c|c|c|c|}
\hline & $\begin{array}{c}\text { Neonatal } \\
n=15\end{array}$ & $\begin{array}{l}\text { Postneonatal } \\
\mathrm{n}=17\end{array}$ & $\begin{array}{l}P \\
\text { değerleri }\end{array}$ \\
\hline Sodyum (meq/L) & $128.4 \pm 6$ & $134.8 \pm 11.6$ & 1 \\
\hline Potasyum (meq/L) & $4.1 \pm 1.6$ & $3.5 \pm 1.1$ & 0.502 \\
\hline Klor (meq/L) & $74.8 \pm 12.8$ & $84.2 \pm 15$ & 0.302 \\
\hline Kalsiyum (mg/dl) & $10.6 \pm 0.6$ & $10.8 \pm 1.4$ & 0.518 \\
\hline Glukoz (mg/dl) & $76.6 \pm 10.3$ & $83.8 \pm 25.6$ & 0.208 \\
\hline Üre (mg/dl) & $51.4 \pm 44.7$ & $35.4 \pm 10.8$ & 0.444 \\
\hline Kreatinin (mg/dl) & $0.6 \pm 0.65$ & $0.28 \pm 0.1$ & 0.076 \\
\hline 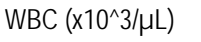 & $8 \pm 2.5$ & $7.8 \pm 2.3$ & 0.737 \\
\hline C-RP (mg/L) & $4.8 \pm 5.6$ & $5.2 \pm 8.3$ & 0.290 \\
\hline $\mathrm{Hgb}(\mathrm{g} / \mathrm{dL})$ & $13.7 \pm 2.7$ & $11 \pm 1.5$ & $<0.001^{*}$ \\
\hline
\end{tabular}

*: $p<0.05$, CRP: C-reaktif protein, Hgb: Hemoglobin WBC: Beyaz kan hücresi

\section{Tartışma}

IHPS, etyolojisi hala net bilinmeyen, mide çıkış obstrüksiyonu sonucu safrası projektil kusmaya yol açan, klinik öykü ve fizik muayene ile tanı konulabilen bir hastalıktır (5). Tedavisinde cerrahi yöntem olarak piloromiyotomi ameliyatı uygulanmakta olup, ilk olarak 1912'de Ramstedt tarafından tanımlanmıştır (7). Hastalığın Asya ve Afrika ırkında daha az sıklıkta görüldüğü bilinmektedir. Bu mevcut çaıışma Somali'nin başkenti Mogadişu'daki Afrika'ı infantlar üzerinde yapıldı. Önceki çalışmalarda IHPS'nin erkeklerde kızlara oranla yaklaşık 4 kat fazla görüldüğü belirtilmiştir (1, 2). Bizim çalışmamızda literatür ile uyumlu olacak şekilde erkek infantlarda kızlara oranla 3 kat daha sık görüldüğü tespit edildi. Tanıda klinik öykü ve fizik muayenenin dışında son yıllarda yüksek duyarlılık ve özgüllüğe sahip olan USG ön plana çıkmaktadır. USG'nin kolay ulaşılabilirliği, ucuz olması ve iyonizan radyasyon içermemesi avantajları arasında sayılmaktadır. Ayrıca USG'nin eşlik eden diğer abdominal patolojileri de göstermesi ve operasyon sonrasında takiplerde kullanılabilmesi büyük avantaj sağlamaktadır (8). Bununla birlikte USG'nin operatör bağımlı olması, gaz artefaktları nedeniyle pilorun optimal görülememesi işlemin limitasyonları arasında sayılabilir. Bu çalışmada yüksek çözünürlüklü USG cihazı kullanılarak ve işlem öncesi midenin sıvı veya gıda ile doldurulması sağlanarak pilor kasının optimal görüntülenmesi sağlandı.

Tablo 4. Hastaların başvuru anındaki laboratuvar bulgularının yaşa göre dağılımlarının ki-kare testi ile karşılaştıııması

\begin{tabular}{|l|l|l|l|l|}
\hline & $\begin{array}{l}\text { Tüm } \\
\text { hastalar } \\
\mathbf{n = 3 2}\end{array}$ & $\begin{array}{l}\text { Neonatal } \\
\mathbf{n = 1 5}\end{array}$ & $\begin{array}{l}\text { Postneonatal } \\
\mathbf{n = 1 7}\end{array}$ & $\begin{array}{l}\boldsymbol{P} \\
\text { değerleri }\end{array}$ \\
\hline Hiponatremi & $20(62.5)$ & $11(73.3)$ & $9(52.9)$ & 0.234 \\
\hline Hipokloremi & $28(87.5)$ & $14(93.3)$ & $14(82.4)$ & 0.349 \\
\hline Hipopotasemi & $16(50)$ & $8(53.3)$ & $8(47.1)$ & 0.723 \\
\hline Hipoglisemi & $8(25)$ & $2(13.3)$ & $6(35.3)$ & 0.152 \\
\hline $\begin{array}{l}\text { Kreatinin } \\
\text { düşüklüğü }\end{array}$ & $16(50)$ & $6(40)$ & $10(58.8)$ & 0.288 \\
\hline Anemi & $15(46.9)$ & $1(6.7)$ & $14(82.4)$ & $<0.001^{*}$ \\
\hline
\end{tabular}

${ }^{*}<0.05$, Değerler sıklık ve yüzde olarak verildi.

IHPS'li hastalarda USG'de en sık hedef işareti ya da target sign (santraldeki ekojen mukoza etrafında halkasal şekilde hipoekoik görünümlü hipertrofik pilor kasının olması) görülür. Buna ek olarak longitudinal bakıda elonge şekilde pilor kasının hipertrofisi, serviks bulgusu (kas kitlesinin sıvı dolu antruma indentasyonu), antral nipple bulgusu (kalınlaşmış çift tabaka mukozanın antruma protrüzyonu) görülebilir. Tüm bunlara ilaveten dinamik yapılan incelemede mide içerisindeki sıvının duodenuma geçişinin oldukça yavaş olduğunun gösterilmesi indirekt bulgu olarak tanıda yardımcı olmaktadır $(8,9)$. Bazı durumlarda pilorospazma bağlı yanIış pozitif sonuçlar ortaya çıkabilir. Bu durum dinamik incelemede sıVı geçişinin değerlendirilmesiyle ve tekrarlayan ölçümlerle önlenebilir (10). Bizim çalışmamızda yanlış pozitifliği gidermek için tekrarlayan ölçümler ve dinamik inceleme yapılarak operasyon öncesi tüm hastaların tanısı kesinleştirildi. Önceki çalışmalara bakıldığında IHPS tanısında en sık ölçülen parametre PK olup çoğunlukla $3 \mathrm{~mm}$ sınır değer olarak kabul edilmiş ve bu değerin üstü patolojik olarak değerlendirilmiştir (8). Buna karşın Blumhagen ve ark. (9) sınır değer olarak $4 \mathrm{~mm}$ ve üzerini kabul etmiştir. Ancak bizim hastalarımızdaki PK değerlerinin ortalaması 4 mm'nin üzerinde olmasına rağmen İHPS'li 8 (\%25) bebekte PK 4 mm'nin altında ölçüldü. Alehossein ve ark. (6) 
yapmış oldukları çalışmada PK, PU ve PÇ değerlerini sırasiyla $4.94 \pm 0.65 \mathrm{~mm}, 20.22 \pm 2.33 \mathrm{~mm}$ ve $13.14 \pm 1.97$ $\mathrm{mm}$ olarak bulmuşlardır. Farklı bir çalışmada PK $4.98 \pm$ $1.04 \mathrm{~mm}, \mathrm{PC} 14.04 \pm 2.39 \mathrm{~mm}$ ve PU $22.16 \pm 4.02 \mathrm{~mm}$ olarak belirtilmiştir (5). Bu mevcut çalışmada literatüre benzer şekilde PK, PÇ ve PU değerleri yüksek bulundu (median değer sırasıyla; 4.8, 11.2 ve $19.5 \mathrm{~mm}$ ). Bu bilgiler ve çalışmamızın verileri ışığında PK'nın $4 \mathrm{~mm}$ üzerinde olması ile tanı kesinleşmekte ve bu değerin 3-4 mm aralığında olması durumunda ise ilave olarak PU, PÇ değerlerinin ölçümü ve dinamik inceleme tanı için yardımcı olacaktır.

Yaş ile USG parametreleri arasındaki ilişkiyi inceleyen birkaç çalışma mevcut olup yazarlar arasında fikir birliği oluşmamıştır. PU ve PK değerlerini yaşa göre karşılaştıran Forster $\mathrm{N}$ ve ark. (3) bu iki parametrenin yaş ile ilişkisi olmadığını ileri sürmesine rağmen Leaphart ve ark. (11) çaIışmalarında PK ve PU ile yaşın ilişkili olduğunu ve yaşça küçük infantlarda bu değerlerin daha düşük ölçüldüğünü belirtmişlerdir. Tüm bunlara ilaveten farkı bir çalışmada sadece PK değeri ile yaş arasında pozitif yönde bir ilişki olduğu ancak diğer parametrelerin benzer olduğu ileri sürülmüştür (5). Bu mevcut çalışmada PK, PÇ ve PU parametreleri neonatal ve postneoatal dönemdeki infantlarda ayrı ayrı ölçülmüş olmakla birlikte bu değerlerin her iki grup arasında benzer olduğu bulundu.

USG bulgularının yanısıra laboratuvar bulguları da hem tanı hem de hastalığın derecesini belirlemede önemli bir rol oynamaktadır. Literatüre baktığımızda IHPS'li olgularda hipokalemi ve hipokloremi görülmesi sık rastlanan bir bulgudur (5). Touloukian R. J. ve ark (12) çalışmalarında ilk başvuru anında 65 hastanın 49 (\%75.3)'unun laboratuvar parametrelerini normal bulmuşlardı. Bizim çalışmamızda 32 hastanın 20 (\%62.5)'sinde hiponatremi, 28 (\%87.5)'inde hipokloremi, 16 (\%50)'sinde hipopotasemi, 8 (\%25)'inde hipoglisemi ve 16 (\% 50)'sında düşük kreatinin değerleri tespit edildi. Ayrıca hastaların 15 (\%46.9)'inde anemi mevcuttu. Anemi görülme oranı postneonatal infantlarda anlamlı oranda yüksekti. Çalışmaya dahil edilen hastaların tamamında kliniğe başvuru anında dehidratasyon ve genel durum bozukluğu vardı. Olgulardaki elektrolit bozukluğunun sık görülmesi; bölgedeki hasta popülasyonunun hastaneye ulaşım imkanlarının kısıtlı olması, sosyal sağlık güvencelerinin olmaması ve kültürel olarak tıp dışı tedavilerin kullanııması ile açıklanabilir.

Bu çalışmanın retrospektif tasarımı ve randomizasyon eksikliği gibi limitasyonları mevcuttu. Ayrıca tek merkezli bir çalışma olduğu için dahil edilen hasta sayısı sınırlıydı. Bu nedenle IHPS'li hastalar arasında USG parametrelerine etki edebilecek değişkenleri açıklığa kavuşturmak için büyük popülasyona dayalı, prospektif ve çok merkezli çalışmalar gereklidir.

Sonuç

Bu çalışmada neonatal ve postneonatal dönemdeki IHPS'li infantların pilor boyutlarının benzer olduğu, yaşın pilor kas ölçümlerini anlamlı oranda etkilemediği sonucuna varıldı. Bununla birlikte neonatal ve postneonatal dönemde fişkırır tarzda safrası kusma ile gelen ve IHPS şüphesi bulunan olgularda, iyonizan radyasyon olmaması ve dinamik inceleme gibi avantajları nedeniyle USG ilk tercih edilecek güvenli ve etkili görüntüleme yöntemidir. USG'de değerlendirilen PK, PÇ ve PU gibi parametreler IHPS tanısında güvenilir olmakla birlikte dinamik incelemeler ile fonksiyonel değerlendirmenin de yapılması kritik rol oynamaktadır. Özellikle gecikmiş vakalarda hastaların klinik ve laboratuvar değerlerini hızlıca düzeltmek adına altın standart olan USG ile gecikmeden tanıya gidilmelidir.

Etik Onam: Bu retrospektif tek merkezli çalışma için yerel etik kurul onayı alındı (Somali Türkiye Mogadişu Recep Tayyip Erdoğan Eğitim ve Araştırma Hastanesi26.12.2019-MSTH/200).

\section{Kaynaklar}

1. Ndongo R, Tolefac PN, Tambo FFM, Abanda MH, Ngowe MN, Fola $\mathrm{O}$, et al. Infantile hypertrophic pyloric stenosis: A 4-year experience from two tertiary care centres in Cameroon. BMC Res Notes. 2018;11(1):1822.

2. Godbole P, Sprigg A, Dickson JAS, Lin PC. Ultrasound compared with clinical examination in infantile hypertrophic pyloric stenosis. Arch Dis Child. 1996;75(4):335-7.

3. Forster N, Haddad RL, Choroomi S, Dilley A V., Pereira J. Use of ultrasound in 187 infants with suspected infantile hypertrophic pyloric stenosis. Australas Radiol. 2007;51(6):560-3.

4. Tashiro A, Yoshida H, Okamoto E. Infant, neonatal, and postneonatal mortality trends in a disaster region and in Japan, 2002-2012: A multiattribute compositional study. BMC Public Health. 2019;19(1):1-13.

5. Ayaz ÜY, Döğen ME, Dilli A, Ayaz S, Api A. The use of ultrasonography in infantile hypertrophic pyloric stenosis: Do the patient's age and weight affect pyloric size and pyloric ratio? Med Ultrason. 2015;17(1):28-33.

6. Alehossein M, Hedayat F, Salamati P, Khavari HA, Mollaeian M. The validity of ultrasound in diagnosing hypertrophic pyloric stenosis. Pakistan J Med Sci. 2009;25(1):65-8.

7. Raveenthiran V. Centennial of Pyloromyotomy. J Neonatal Surg. 2013;2(1): 1-8.

8. Costa Dias S, Swinson S, Torrão H, Gonçalves L, Kurochka S, Vaz $\mathrm{CP}$, et al. Hypertrophic pyloric stenosis: Tips and tricks for ultrasound diagnosis. Insights Imaging. 2012;3(3):247-50.

9. Blumhagen D, George H, Noble S. Muscle thickness in hypertrophic pyloric stenosis: sonographic determination. AJR Am J Roentgenol. 1983;140:221-3.

10. Riccabona M, Weitzer C, Lindbichler F, Mayr J. Sonography and color Doppler sonography for monitoring conservatively treated infantile hypertrophic pyloric stenosis. J Ultrasound Med. 2001;20(9):997-1002. 11. Leaphart CL, Borland K, Kane TD, Hackam DJ. Hypertrophic pyloric stenosis in newborns younger than 21 days: remodeling the path of surgical intervention. J Pediatr Surg. $2008 ; 43(6): 998-1001$.

12. Touloukian RJ, Higgins E. The spectrum of serum electrolytes in hypertrophic pyloric stenosis. J Pediatr Surg. 1983;18(4):394-7. 